\title{
EU-DEMO divertor: cassette design and PFCs integration at pre-conceptual stage
}

\author{
Ugo Bonavolontà*a, Christian Bachmann ${ }^{\mathrm{b}}$, Domenico Coccorese ${ }^{\mathrm{a}}$, Giuseppe Di Gironimo ${ }^{\mathrm{a}, \mathrm{c}}$, Vito Imbriani ${ }^{\mathrm{a}}$, \\ Domenico Marzullo, ${ }^{\mathrm{a}, \mathrm{d}}$, Giuseppe Mazzone ${ }^{\mathrm{e}}$, Christian Vorpahl ${ }^{\mathrm{b}}$, Jeong-Ha You. \\ ${ }^{a}$ Consorzio CREATE, Via Claudio 21, 80125 Napoli, Italy \\ ${ }^{b}$ Power Plant Physics \& Technology, EUROfusion, Garching, Germany \\ 'Univ. of Naples Federico II, DIETI, Via Claudio 21, 80125 Napoli, Italy \\ ${ }^{d}$ Univ. of Trieste, Department of Engineering and Architecture, Via Alfonso Valerio, 6/1, 34127 Trieste (Italy) \\ ${ }^{e}$ ENEA Department of Fusion and Technology for Nuclear Safety and Security, via E. Fermi 45, 00044 \\ Frascati, Italy \\ ${ }^{f}$ Max-Planck-Institute for Plasma Physics, Boltzmannstr. 2, 85748 Garching, Germany \\ *Corresponding author: ugo.bonavolonta@consorziocreate.it
}

The pre-conceptual design of the DEMO divertor cassette with a novelty, alternative path of the main cooling pipes inside cassette body is presented in this paper, focusing on cassette design and Plasma Facing Components (PFC) integration. The divertor cassette design is reviewed, considering recent updates in the DEMO configuration model as presented by the Programme Management Unit (PMU) in 2018. The new configuration requires the cooling pipes to be integrated inside the cassette body. The components affected by these changes and the impact on the divertor design are analyzed. The study focuses on a new integration system between cassette and cooling pipes. The paper describes the integration on the new cassette geometry and the divertor sub-systems. The design activities related to this system are discussed in detail in terms of CAD modeling and considerations with respect to manufacturing such as welding technologies and non-destructive testing.

Keywords: DEMO, divertor cassette, divertor target, cooling pipes

\section{Introduction}

This paper discusses recent update in pre-conceptual design for the DEMO divertor Cassette Body (CB). Considering new baseline in DEMO configuration model presented by the Programme Management Unit (PMU) in 2017, through Systems Engineering (SE) approach the divertor CAD model is reviewed [1]. Today the DEMO project is in a pre-conceptual phase and divertor configuration is still under investigation. The main issues identified from the analyses performed on the 2018 divertor model (presented in [7]) were related to the divertor shielding function as well as to divertor cooling operating condition. On these bases, the divertor model discussed in this paper has been reviewed to satisfy the following requirements:

- Maximize thickness and dimension of Cassette Body in the poloidal plane to improve shielding of TF coils in the lower port area;

- Provide shielding to the Plasma Facing Components (PFCs) diffusers and manifolds

In 2015, the activity on DEMO divertor pre-conceptual design phase is started with baseline model and the design activities as described in [2][3]. In addition to a change of the Cassette Body (CB) baseline in a first phase of the activity, an alternative configuration path of cooling system was studied, Plasma Facing Component (PFC). For better protection of latter system, hollows on cassette body has been modelled and inside it, pipes, manifolds and diffusers have been inserted.

The divertor cassette design has been adapted to the new volume allocation and main features have been developed, as the "reflector plates" for the inlet diffuser protection, a new "shielding liner" configuration for the vacuum pumping hole protection and wishbone design for cassette to vacuum vessel interface.

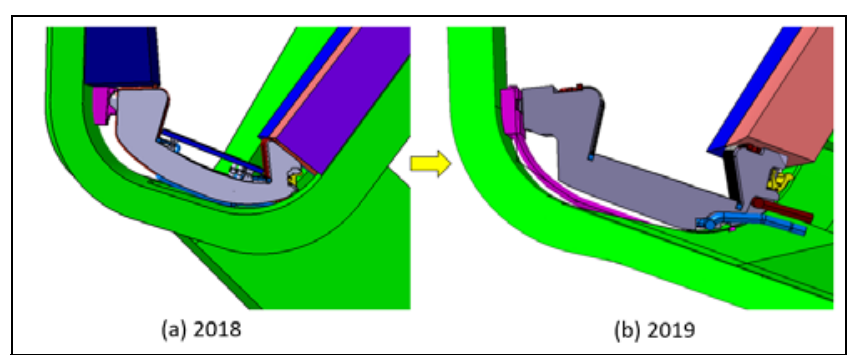

Fig. 1: (a) The 2018 divertor model (b) The 2019 divertor model. 


\section{DEMO divertor cassette body design}

In 2018 DEMO divertor cassette design was modelled to adapt its geometry to the new PFC configuration. In fact, to improve fluid-dynamic behaviour and avoid pressure drops, PFC pipes have a smooth curvature and a bigger diameter in the same way also the interface with cassette body will change.

The modelling of the new divertor cassette represents the result of an evolution of the activity developed in recent years, whose results are considered high level references [2][3]:

- Inlet cooling water at $3.5 \mathrm{MPa}-180^{\circ} \mathrm{C}$, confirmed from the analyses performed in the first design phase [4];

- The Plasma Facing Components (PFCs) cooling system configuration selected during the first pre-conceptual design phase to be integrated in the new cassette shape;

- Eurofer97 material for divertor cassette: ribs thickness $20 \mathrm{~mm}$; external plate thickness 30 $\mathrm{mm}$ (considering the stress analyses performed in the first phase)[5].

The developed of new divertor is shown in Fig. 2, the main change of the geometry is shown in the inboard area where the cassette profile is no curved but squared, in this way there is space to allocate a support rail. The Fig. 4 shows also the resulting of shielding liner from the pre-conceptual phase with increasing of the dimension and the introduction of new components like Reflector Plates (RB) to protect the inlet diffusers. The toroidal dimensions are the same of 2017, with 48 divertors allocated in 16 sectors. The activities on divertor cassette design in the new baseline moved with the same reference position of the Inner Vertical Target (IVT) and Outer Vertical Target (OVT) developed in 2017. The strike point on the target is in the poloidal centre of the $700 \mathrm{~mm}$ straight part of the vertical targets. The strike area is assumed to have $100 \mathrm{~mm}$ poloidal extension and the control range of the strike point is estimated $\sim \pm 300 \mathrm{~mm}$ (Fig. 2).

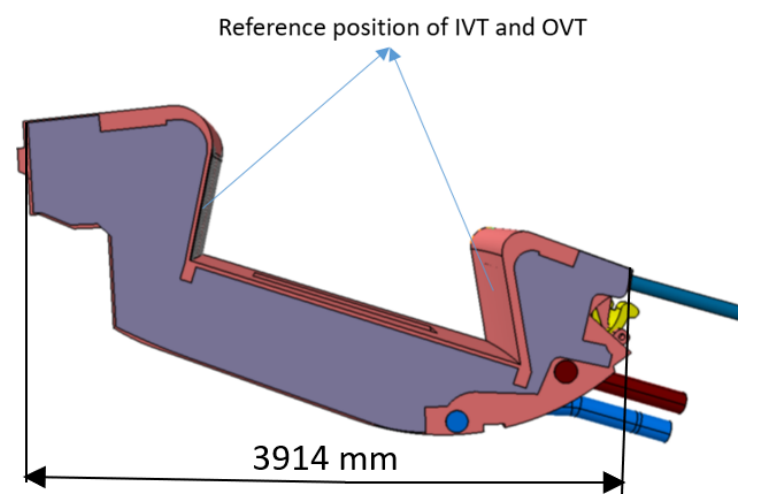

Fig. 2: Divertor 2018 baseline (Rose) - IVT and VT reference position

Since no relevant changes in the pressure and operating temperature, the cassette internal ribs structure assumed similar to the previous design. Fig. 3 shows internal ribs layout: 4 toroidal ribs and 3 poloidal ribs driving the $\mathrm{CB}$ coolant. The ribs dimensions are: thickness $20 \mathrm{~mm}$ and the maximum distance between two poloidal ribs is 350 $\mathrm{mm}$.

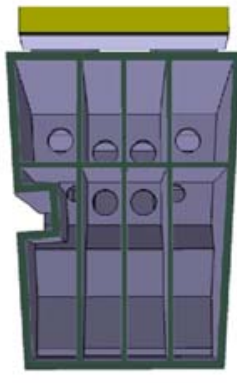

Inboard

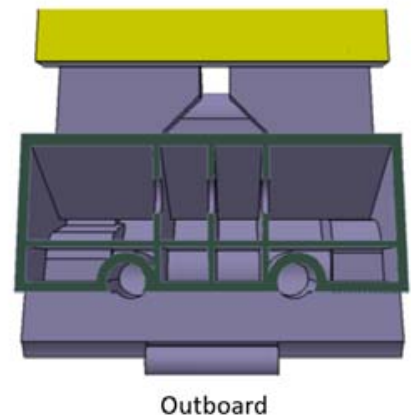

Outboard
Fig. 3: Divertor CB toroidal section at inboard (left) and outboard (right), internal rib of $20 \mathrm{~mm}$, external ribs of $30 \mathrm{~mm}$.

As previously mentioned, two different cooling circuits integrated on the cassette body, due to the different operating temperatures of the Eurofer97 CB and PFCs.

Fig. 4 shows different views of the current divertor CAD model. Table 1: Volume and Mass divertor values., reports the main values of volume and masses for cassette body and shielding liner, both in normal operating condition (with coolant) and in maintenance scenarios (without coolant). 


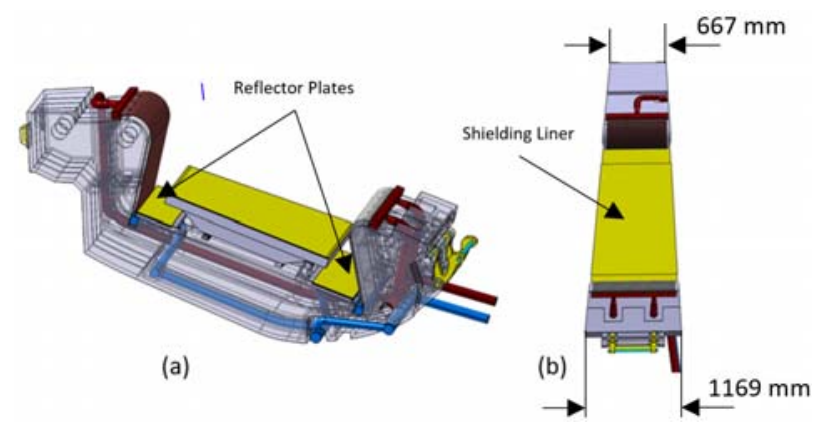

Fig. 4: 2019 Divertor CAD model. (a) isometric view, (b) top view.

The total mass during installation (without cooling) is increased from 6.2 tons in 2018 model to 7.2 tons in the new model with the inclusion of a new component in the divertor configuration.

Table 1: Volume and Mass divertor values.

\begin{tabular}{|c|c|c|}
\hline \multirow{3}{*}{$\begin{array}{l}\text { Cassette } \\
\text { EUROFER }\end{array}$} & Density $\left[\mathrm{Kg} / \mathrm{m}^{3}\right]$ & 7750 \\
\hline & Volume $\left[\mathrm{m}^{3}\right]$ & 0,729 \\
\hline & Mass [Kg] & 5650 \\
\hline \multirow{3}{*}{ Water } & Density $\left[\mathrm{Kg} / \mathrm{m}^{3}\right]$ & 1000 \\
\hline & Volume $\left[\mathrm{m}^{3}\right]$ & 1,268 \\
\hline & Mass [Kg] & 1268 \\
\hline CB (operating condition) & Total Mass [Kg] & 6918 \\
\hline \multirow{2}{*}{ Liner } & Volume $\left[\mathrm{m}^{3}\right]$ & 0,149 \\
\hline & Mass [Kg] & 1157 \\
\hline \multirow{2}{*}{ Water } & Volume $\left[\mathrm{m}^{3}\right]$ & 0,125 \\
\hline & Mass [Kg] & 125 \\
\hline Liner (operating condition) & Total Mass [Kg] & 1282 \\
\hline \multirow{2}{*}{$\begin{array}{c}\text { Reflector Plates } \\
\text { (Inboard and Outboard) }\end{array}$} & Volume $\left[\mathrm{m}^{3}\right]$ & 0,02 \\
\hline & Mass [Kg] & 155 \\
\hline \multirow{2}{*}{ Water } & Volume $\left[\mathrm{m}^{3}\right]$ & 0,017 \\
\hline & Mass [Kg] & 17 \\
\hline Reflector plate (operating condition) & Total Mass [Kg] & 172 \\
\hline CB+Liner (operating condition) & Total Mass [Kg] & 8200 \\
\hline CB+Liner (installation and RH) & Total Mass [Kg] & 6807 \\
\hline CB+Liner+RPs (operating condition) & Total Mass [Kg] & 8372 \\
\hline CB+Liner+RPs (installation and RH) & Total Mass [Kg] & 6962 \\
\hline Divertor (operating condition) & Total Mass [Kg] & 8520 \\
\hline Divertor (installation and RH) & Total Mass [Kg] & 7210 \\
\hline
\end{tabular}

From a mechanical evaluation of an alternative path of the cooling system inside cassette body, a manufacturing problem has emerged. Therefore, in the second phase of activity a possible solution has been studied, as discussed in section 4. In parallel, the design activities on the 2018 baseline divertor focused also on development of main sub-components, in particular the shielding liner for radiation protection through the vacuum pumping hole and the introduction of new components reflector plates for radiation protection of inlet diffuser.

\subsection{Shielding Liner and Reflector Plate design}

The protection system for the vacuum pumping hole from radiation heat and neutron flux has implemented also to inlet diffuser inside cassette body. In the first case, protection system consists in a plate, named shielding liner, with an internal structure similar to the water cooled blanket First Wall (FW), whose structure has been analysed against thermal loads. The second case consist in two systems, named Reflector Plates (RPs), similar to shielding liner, both are allocated above inlet diffusers and they are connected to each other with some pipes. The new shielding liner design has been adapted to the new volume allocation as shown in Fig. 5.

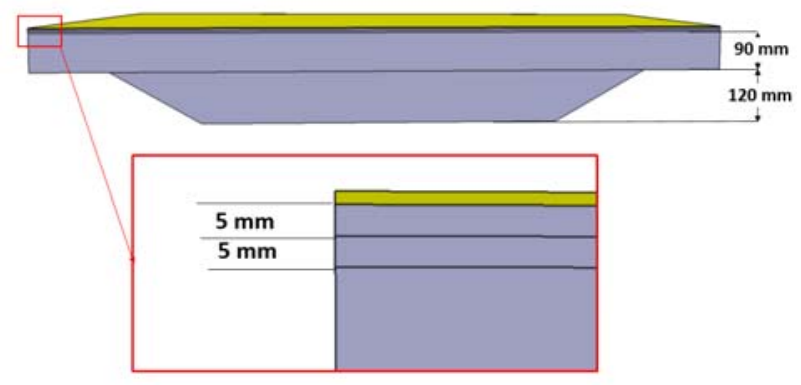

Fig. 5: Shielding Liner, dimensions of single layers.

The shielding liner shows a configuration similar to 2018, composed by four distinct layers, but with great dimensions different. For a better adapt to the cassette shape the Liner design moved from a rectangular to a trapezoidal shape and the second major change concerns the steel layer which has a more massive shape Fig. 5, Fig. 6. The first layer has a different geometry; it is composed of a layer and a base at the point where it fixed to the box, for a total size of $210 \mathrm{~mm}$.

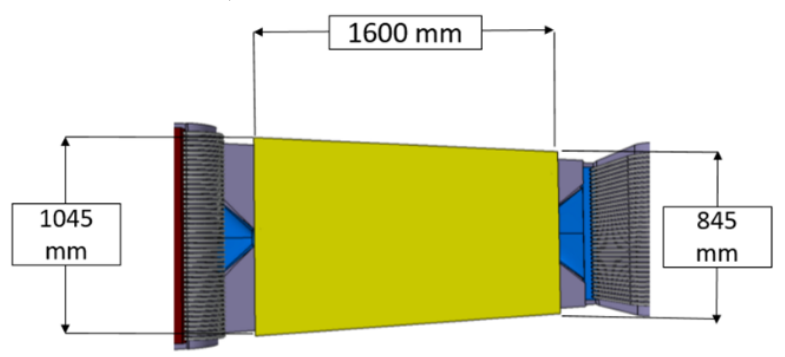

Fig. 6: Upgrade Liner design

The first layer is a $210 \mathrm{~mm}$ in thickness Eurofer97 plate crossed by semi-circle shaped slots for coolant flow. Both second and third layers are $5 \mathrm{~mm}$ in thickness Eurofer97 plats joined together to form an array of $8 \mathrm{~mm}$ circular cooling channels to remove the significant surface heat load due to core and X-point radiation, assumed to be about 1.5 MW/m² (Fig. 7). 

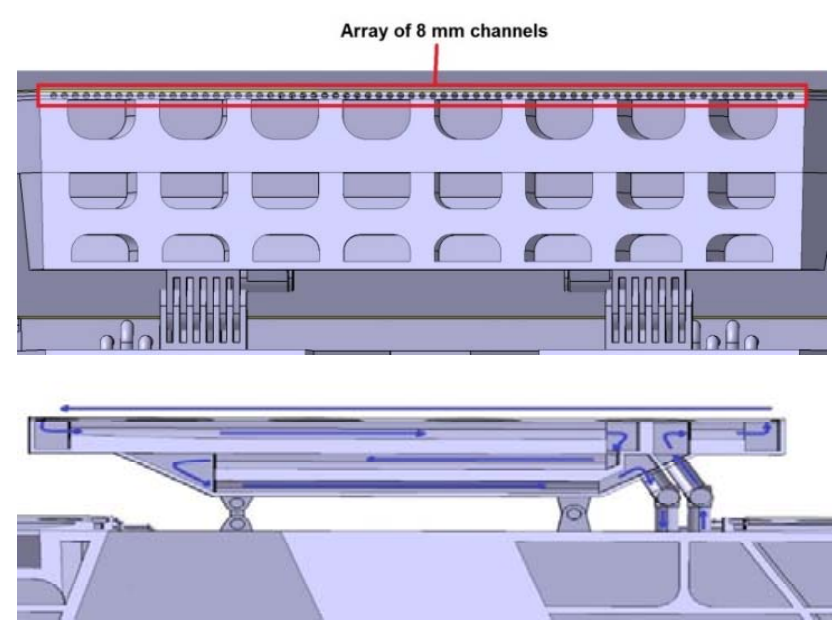

Fig. 7: Liner cross-section and Coolant flow through the shielding liner.

The Eurofer structure covered with $3 \mathrm{~mm}$ thick tungsten. These changes involve in a complex internal circuit, as shown in Fig. 7, the water flux passes through first layer twice, before arriving the smallest channels through internal manifolds. The channels are fan-shaped to cover the cassette trapezoidal shape.

Fig. 7 shows a section of the shielding liner integrated on the divertor cassette design, highlighting the coolant flow path. The Reflector Plates have the same internal configuration of the Shielding Liner, in particular his geometry is near to 2018 liner cad model and they are allocate above two inlet diffusers in inboard and outboard area Fig. 8. RP belong to Cassette Body cooling system in which, the cooling water flows from the cassette (at $180^{\circ}, 3.5 \mathrm{MPa}$ ) to the first shielding liner layer, coming back in the cassette through the shielding liner back plate. These two diffusers shielding are connected with 4 pipes to improve water flow between area to other one of cassette.
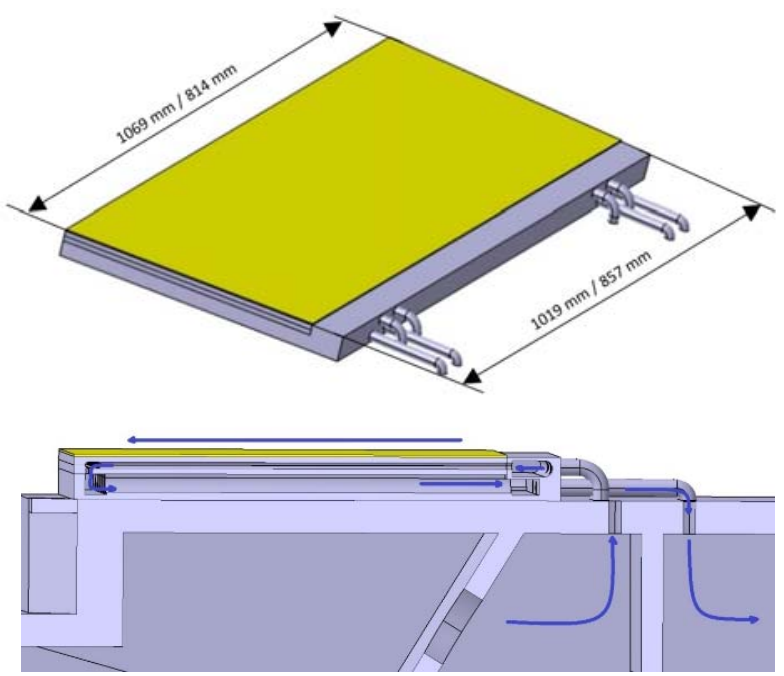

Fig. 8: Reflector Plate, cross-section and coolant flow
The first layer is a $24 \mathrm{~mm}$ in thickness Eurofer97 plate crossed by semicircle-shaped slots. Also, second and third layers are in Eurofer with $8 \mathrm{~mm}$ thick joined together to form an array of $6 \mathrm{~mm}$.

\section{Manufacturing consideration}

The work previously described, with an alternative pipes configuration allocate inside cassette was established from PMU in a first phase of 2019. In this way, it was possible to maximize the size of Cassette Body and in the same time some portions of the $\mathrm{CB}$ improve the protection of the pipes and manifolds. However, to the requirements described in first section it is necessary to add another requirement:

The geometric feasibility for manufacturing of divertor system.

A careful analysis on this requirement has shown a high complexity in the manufacturing approach. To resolve this problem, it was decided to modify the divertor's layout to simplify the manufacturing process and preserve mechanical proprieties, in the same time.

The changes applied for simplified manufacturing processes are three:

- The first main change focused on outboard area where outlet PFC pipes allocated inside cassette body, in an impervious space to apply an assembly process. For this reason, the outlet pipes on external sides of cassette body are moved through cavity to have a better access in both during manufacture and maintenance phases Fig. 9.

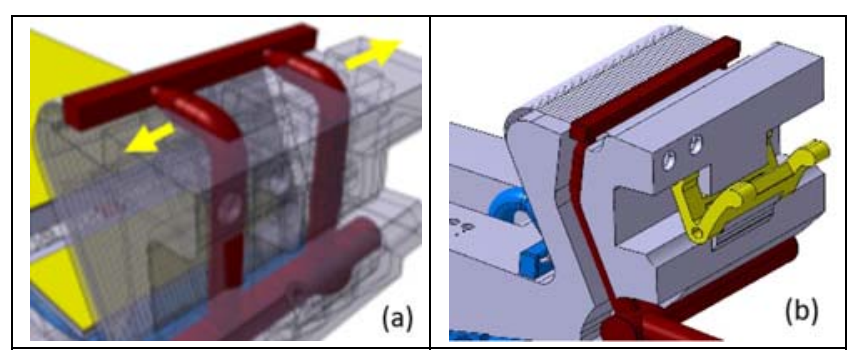

Fig. 9: First change, Outlet pipes moved on external surfaces, (a) first phase (b) second phase.

- The second change are diffusers allocation, the cavity present on the divertor cassette reduced the water volume compromising the function of all cooling system of the cassette body. For this reason, the diffusers have been removed from the cassette body and as consequence, the Reflector Plates will be reallocated Fig. 10. 


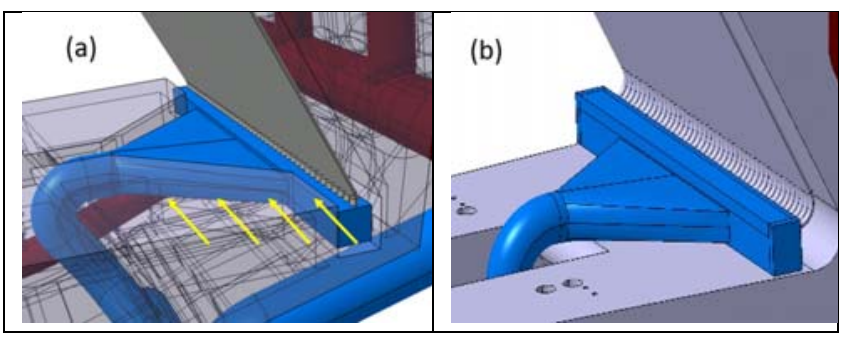

Fig. 10: Second change, diffuser moved outside cavity of cassette body, (a) first phase (b) second phase.

This displacement is useful not only to have more space inside cassette body for water flow, but the main requirement is manifold and Plasma Facing unit (PFu) assembly. The diffuser allocate inside cassette geometry makes it almost impossible the access to weld the pipes in $\mathrm{CuCrZr}$ to the manifold. Therefore, a geometric change to manifold was applied, more details in section 3.1.

- The third change involves in all PFC pipes curvature, they converted in square section manifolds. This design is more flexible and even if it complicates the fluid-dynamic effect, it greatly simplifies the assembly process.
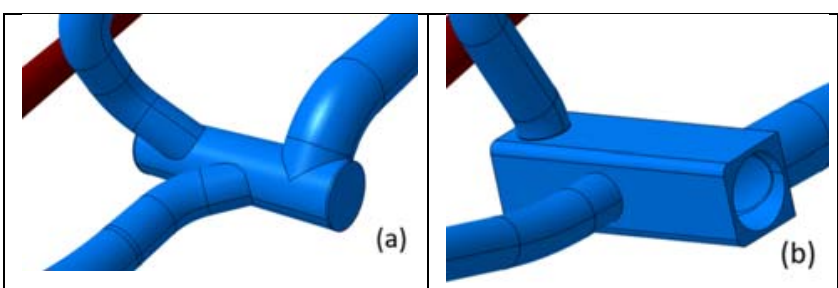

Fig. 11: Third change, change of the manifolds shape, (a) first phase (b) second phase.

Further studies will be carried out in the coming months to find a compromise that meets all the requirements.

\subsection{Assembly process}

Following the study on the geometric feasibility for divertor system manufacturing, it was decided to define a first assembly hypothesis of the PFCs on the cassette body. Starting from the cassette body it was thought to insert the outlet pipes in the cavities made on the external surfaces, and then assembled to the respective manifolds, Fig. 12. (a)
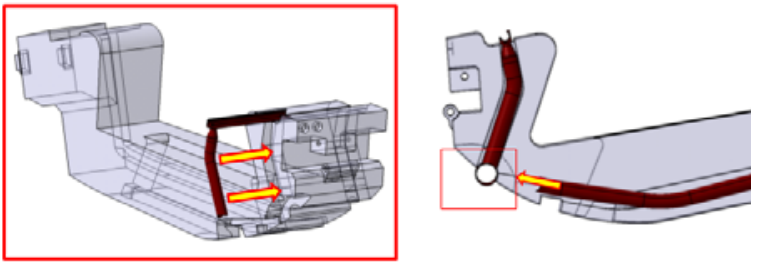

(b)

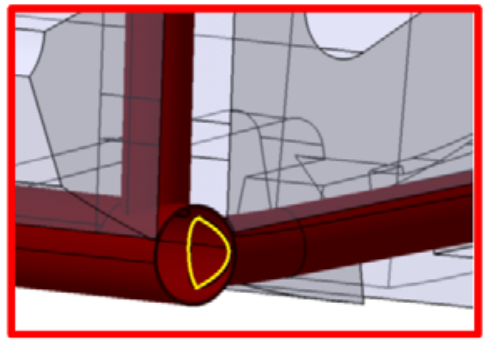

Fig. 12: (a) insertion of pipes in the cavity, (b) example of welding, yellow curve.

To weld pipes and manifolds it is necessary to have free access without obstructions, for this reason, the manifolds have different shapes but they consist of two parts. In this way, it is possible to apply the weld and in a second moment close all and to apply an external weld, as visible in the Fig. 13.

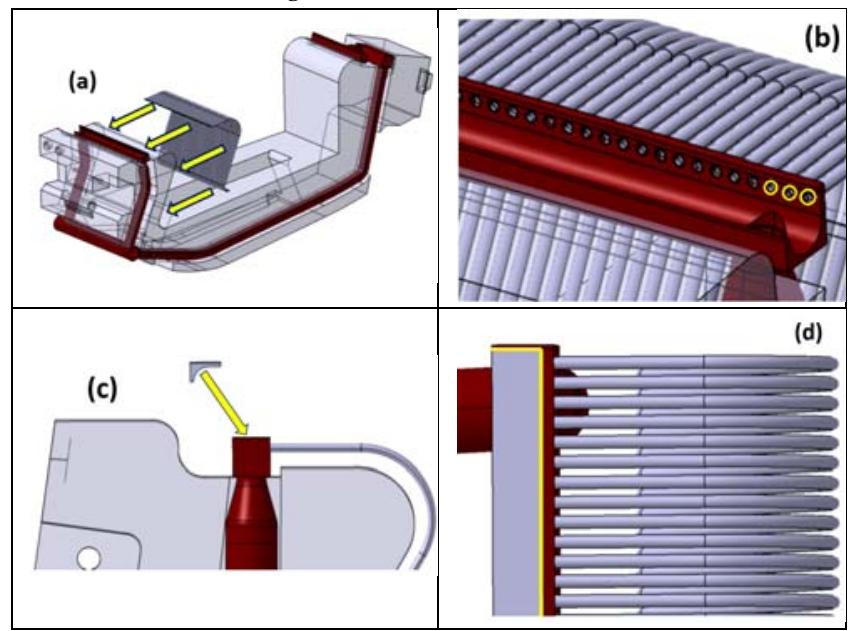

Fig. 13: (a) CuCrZr pipes allocation, (b) details of welding pipes, yellow curve, (c) application of cover to complete manifold geometry, (d) details of external welding, yellow lines

The Fig. $13 b$, also shows the welding step of the $\mathrm{CuCrZr}$ pipes with the manifold. The manifold shows a longitudinal section in which there is free access to all $\mathrm{CuCrZr}$ pipes (Fig. 13 b); once assembled it closed with a cover that completes the manifold (Fig. 13 c) and allows a simple external welding, as show in the Fig. 13. This process can be repeat for all the areas connected to the targets following the same procedure. 


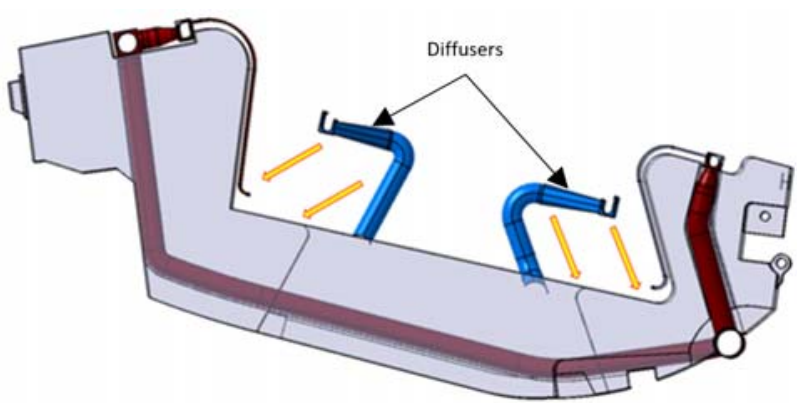

Fig. 14: Application of inlet pipes through vacuum pumping hole.

Finally, the inlet pipes and diffusers inserted from above through the vacuum pumping hole. Once in position the rest of the structure have been welded and assembled, Fig. 14.

For the moment, this described is a hypothetical approach that will have a real feedback, then later.

\section{Conclusions}

Starting from the results of the first pre-conceptual design phase, the EU-DEMO divertor CB design has been reviewed. According to a system engineering approach, the CB design and the PFCs integration has been performed combining the results of the previous evaluations (in terms of thickness and layouts) with the new volume allocation and interfaces.

For the vacuum vessel, protection from irradiation through vacuum pumping hole have been investigate, resulting in the introduction of the Reflector Plates and an improvement of Shielding Liner.

The cassette body presents a global geometry similar to 2018 divertor but with some difference useful to maximize thickness and dimension of Cassette Body in poloidal plane and to protect the PFC cooling tube. To satisfy these requirements an alternative configuration with the PFC inside the cassette body has been study.

In a second phase of the activity the feasibility of manufacturing divertor system was studied. The alternative configuration seemed very complex so to simplify this procedure some geometric modifications have been apply and finally everything has been justified through a hypothetical assembly process.

\section{Acknowledgments}

This work has been carried out within the framework of the EUROfusion Consortium and has received funding from the Euratom research and training programme 2014-2018 and 2019-2020 under grant agreement No 633053. The views and opinions expressed herein do not necessarily reflect those of the European Commission.

\section{References}

[1] Di Gironimo, G., et al. "Iterative and Participative
Axiomatic Design Process in complex mechanical assemblies: case study on fusion engineering." International Journal on Interactive Design and Manufacturing (IJIDeM) 9.4 (2015): 325-338.

[2] Marzullo, D., et al. "Systems engineering approach for preconceptual design of DEMO divertor cassette." Fusion Engineering and Design 124 (2017): 649-654.

[3] You, J. H., et al. "Progress in the initial design activities for the European DEMO divertor: Subproject "Cassette"." Fusion Engineering and Design 124 (2017): 364-370.

[4] Di Maio, P. A., et al. "Analysis of steady state thermalhydraulic behaviour of the DEMO divertor cassette body cooling circuit." Fusion Engineering and Design 124 (2017): 437-441.

[5] Frosi, P., et al. "Structural analysis of DEMO divertor cassette body and design study based on RCC-MRx." Fusion Engineering and Design 124 (2017): 628-632.

[6] Mazzone, Giuseppe, et al. "Choice of a low operating temperature for the DEMO EUROFER97 divertor cassette." Fusion Engineering and Design 124 (2017): 655658

[7] Marzullo, D., Bachmann, C., Coccorese, D., Di Gironimo, G., Frosi, P., Mazzone, G., \& You, J. H. (2019). Progress in the pre-conceptual CAD engineering of European DEMO divertor cassette. Fusion Engineering and Design, 146, 942-945. 